\title{
POSTERIOR CAPSULAR CHANGES AND ITS ASSOCIATION WITH POSTERIOR CHAMBER INTRAOCULAR LENS SURFACE CHANGES AFTER EXTRACAPSULAR CATARACT EXTRACTION
}

\author{
Nameeth D. A. D'souza1, Prashanthkumar Narayan Achar²
}

${ }^{1}$ Assistant Professor, Department of Ophthalmology, K. S. Hegde Medical Academy, Mangalore.

${ }^{2}$ Assistant Professor, Department of Ophthalmology, Srinivas Institute of Medical Sciences and Research Center, Mangalore.

\section{ABSTRACT}

\section{BACKGROUND}

Posterior Capsular Opacification is the most frequent complication of cataract surgery. There are few studies that determine the changes in the lens surfaces with the posterior capsular changes. The objectives of the present study were to report intraocular lens surface changes and posterior capsular changes after extracapsular cataract extraction with posterior chamber intra-ocular lens (ECCE-PCIOL) implantation surgeries, and to determine the factors influencing the anterior surface changes.

\section{MATERIALS AND METHODS}

In an observational study done at Father Muller Medical College Hospital, Kankanady, Mangalore from October 2004 to March 2006, one hundred patients who were undergoing surgery for cataract were recruited. The patients underwent ECCE- PCIOL surgery. Post-operative evaluation was done on the $1^{\text {st }}$ post-op day and at the end of $1^{\text {st }}, 3^{\text {rd }}, 6^{\text {th }}$ week, 6 months and 9 months. Patients were subjected to slit-lamp evaluation and changes in anterior and posterior surfaces of IOL and posterior capsule were photographically documented.

\section{RESULTS}

In $10 \%$ of the patients, there were similar IOL surface changes and PC changes that are statistically insignificant. There was no statistical significance in IOL surface changes with PC changes seen in other factors like systemic diseases i.e., diabetes, hypertension, type of surgery i.e. small incision cataract surgery (SICS) and extracapsular cataract surgery (ECCE), type of capsulotomy. The significant statistical association between IOL surface changes and PC changes is seen in intraocular lens (IOL) sulcus insertion. There was no significant association between anterior and posterior IOL surface changes with posterior capsular changes after ECCE-PCIOL surgeries.

\section{CONCLUSION}

There is significant association between the intraocular lens surface changes and posterior capsular changes in "IOL-sulcus insertion" when compared to "IOL-bag insertion". There is no significant association between intraocular lens surface changes and posterior capsular changes after extracapsular cataract extraction-posterior chamber intraocular lens implantation surgery. Type of surgery, type of capsulotomy (can-opener and capsulorhexis) and systemic diseases have no significant effect on similar intraocular lens surface changes and posterior capsular changes.

\section{KEYWORDS}

Posterior Capsular Opacification; Intra-Ocular Lens; Cataract Surgery; Sulcus Insertion; Bag Insertion.

HOW TO CITE THIS ARTICLE: D'souza NDA, Achar PN, Posterior capsular changes and its association with posterior chamber intraocular lens surface changes after extracapsular cataract extraction. J. Evolution Med. Dent. Sci. 2017;6(48):3698-3702, DOI: $10.14260 /$ Jemds/2017/798

\section{BACKGROUND \\ Pearl formation and capsular fibrosis represent the two types of after-cataract. ${ }^{1}$ The term "after-cataract" is preferred over "capsule opacification" as the capsule remains transparent. The term posterior capsular opacification (PCO) has wide spread use and is accepted. ${ }^{2}$ Such changes derive from LECs. ${ }^{3}$ PCO is the most frequent complication of cataract surgery. Many changes in surgical techniques, material of intraocular}

Financial or Other, Competing Interest: None.

Submission 24-04-2017, Peer Review 03-06-2017,

Acceptance 09-06-2017, Published 15-06-2017.

Corresponding Author:

Prashanthkumar Narayan Achar

Assistant Professor

Department of Ophthalmology,

Srinivas Institute of Medical

Sciences and Research Center

Mangalore.

E-mail: pnachar2012@gmail.com

DOI: $10.14260 /$ jemds $/ 2017 / 798$ lenses and newer design of lenses have addressed to reduce the PCO rate. Incidence of posterior capsular opacification is an age-related phenomenon and its incidence approaches $100 \%$ in paediatric cases as concluded by Sophie Maedel in a meta-analysis. ${ }^{1}$ Occurrence of PCO is relatively lower in older patients in comparison to young patients. ${ }^{4,5}$ PCO changes include fibrotic type, Elschnig's pearls, bladder cells deposition, Soemmering's ring and capsular wrinkles.

Among the factors that contribute to the formation of posterior capsular changes are intraocular lens material, shape, surface modifications, pre- and post-op medications, type of surgery and capsulotomy according to previous reports. ${ }^{6}$ The intraocular lenses have a role in preventing and promoting posterior capsular changes.7,8

Lens epithelial cells (LECs) transdifferentiate to myofibroblastic cells, producing collagen fibres around the anterior capsulotomy margins. ${ }^{1}$ These fibres cause the anterior capsulotomy margin to adhere to the posterior capsule to form a closed space in which LECs differentiate into lens fibre cells. These regenerated lens fibres form 
Soemmering's ring. Elschnig's pearls are formed due to leaking of lens fibre cells from adhered capsule. ${ }^{9}$ Adhesion is an important protective factor against Elschnig's pearl formation with can-opener technique, capsulotomy opening is usually larger than the IOL optic, which allows the capsulotomy margins to contact the posterior capsule directly. With continuous curvilinear capsulorhexis (CCC), however, the capsular opening is usually smaller than the optic and the optic inside the bag hinders the adhesion of capsulotomy margins. ${ }^{3,10}$ More lens fibre cells leak through the adhesion when biconvex lens is implanted resulting in Elschnig's pearl formation. ${ }^{9}$

The treatment of PCO is mainly Nd:YAG capsulotomy which is associated with many complications.4,9 IOL material and design influences the results of this procedure. ${ }^{11}$ As this procedure involves considerable cost, understanding the nature, causes and prevention of PCO is paramount in any cataract surgery to improve the results.

There are few studies that determine the changes in the lens surfaces like pigment depositions, crystal depositions, scratch marks, blood clot depositions, visco-material deposition with the posterior capsular changes. The objectives of the present study were to report intraocular lens surface changes and posterior capsular changes after extracapsular cataract extraction with posterior chamber intra-ocular lens (ECCE-PCIOL) implantation surgeries and to determine the factors influencing the anterior surface changes.

\section{MATERIALS AND METHODS}

In an observational study done at Father Muller Medical College Hospital, Kankanady, Mangalore from October 2004 to March 2006, one hundred patients who were undergoing surgery for cataract were recruited. Study design was prospective observational study. Institutional ethics committee approved this study. A thorough informed consent procedure was followed at the beginning of the study, at the time of admission of the patients.

After noting the history, preoperative work up of the patients was done, which included visual acuity, torch light and silt lamp evaluation, dilate and fundus examination. Syringing of the nasolacrimal duct was done, intraocular and blood pressure was noted and urine was screened for diabetes mellitus. A-scan biometry was done and posterior chamber intraocular lens (PCIOL) power was calculated.

Patients with posterior capsular tear, small pupil and intraocular diseases were excluded from the study.

\section{Sample Size}

Based on previous data, incidence of capsular opacification was $6 \%$ post ECCE and PCIOL implantation at the end of $1^{\text {st }}$ year. 12,13

Sample size was calculated using the following formula, standard normal variate, $\mathrm{Z}=1.96$ (for $\mathrm{p}<0.05$ ), absolute error $\mathrm{d}=0.05$ and prevalence $\mathrm{p}=0.06$

Sample size $=\mathrm{Z}_{1-\alpha / 2^{2}} \mathrm{p}(1-\mathrm{p}) / \mathrm{d}^{2}$

$=(1.96)^{2} * 0.06(1-0.06) /(0.05)^{2}$

$=86$

Accounting for $10 \%$ drop out rate, the sample size was rounded off to 100 .

The patients underwent extracapsular cataract extraction (ECCE) with posterior chamber intraocular lens (PCIOL) surgery either by conventional extracapsular cataract extraction or by manual small incision technique (SICS). One eye of each subject was included in the study. Preoperatively, the pupils were dilated using 1\% tropicamide and $10 \%$ phenylephrine eye drops. Small incision scleral tunnel or limbal incision was made. The type of anterior capsulotomy was made either by continuous curvilinear capsulorhexis (CCC) or by can-opener technique. Cortex was washed with using Simcoe's two-way irrigation aspiration cannula. PCIOL was inserted in the posterior chamber with the loops in the bag or in the sulcus.

The type of IOL was three piece PMMA. Significant events during surgery were noted.

The material used, trade name, company name and batch no. of IOLs, irrigating solution, viscoelastic were noted down. The company name, batch no. and date of manufacture, preoperative and postoperative medications used were noted.

Post-operative evaluation was done on the $1^{\text {st }}$ post-op day and at the end of $1^{\text {st }}, 3^{\text {rd }}, 6^{\text {th }}$ week, 6 months and 9 months. Visual acuity and slit-lamp examination was done to find out the status of the cornea, any evidence of uveitis or retained cortical matter, PC and IOL surface changes. Fundus evaluation was done to rule out any pathology causing diminution of vision.

Patients were subjected to slit-lamp evaluation and changes in anterior and posterior surfaces of IOL and posterior capsule were photographically documented (by using 4.2-megapixel digital camera).

Changes like - fibrous sheet, indentation, uveal pigment, capsule thready lines, blood clots, grooves, crystalline plaques, greasy deposition, balloon cells, divergent lines, wrinkles, if noted, photographs were taken and documented. Posterior capsular opacification changes were compared with lens anterior surface changes and categorised into similar and dissimilar categories. These categories were compared with IOL bag and sulcus insertion.

\section{Statistical Analysis}

Results were expressed in percentages. Chi square test is used to determine the statistical significance. Values less than 0.05 were considered significant.

\section{RESULTS}

Out of 100 patients (54 males and 46 females), 33 were aged between 60 to 70 years, 20 were more than 70 years. Twenty-eight patients underwent extracapsular cataract surgery (ECCE) and 72 patients underwent small incision cataract surgery (SICS). Thirty-five patients underwent canopener capsulotomy and 65 patients underwent continuous curvilinear capsulotomy. IOL was placed in the capsular bag in 96 patients and in 4 patients in sulcus.

Maximum similar IOL surface and posterior capsular changes seen in the age group of 60-70 years and minimum similar changes in the age group of 30-40 years without any statistical significance. Five (10.86\%) out of 46 female patients and five $(9.25 \%)$ out of 54 male patients had similar IOL surface changes and posterior capsular changes. There is no statistical significance between two sexes. One $(3.57 \%)$ in 28 ECCE and nine $(12.5 \%)$ in 63 SICS patients had similar IOL surface and posterior capsular changes which is statistically insignificant. 
Four (11.42\%) out of 35 patients who underwent canopener capsulotomy, six $(9.25 \%)$ out of 65 patients who underwent continuous curvilinear capsulotomy had similar IOL surface and posterior capsular changes which is statistically insignificant.

\begin{tabular}{|c|c|c|c|c|c|}
\hline & & & $\begin{array}{c}\text { Dissimilar } \\
\text { Changes }\end{array}$ & $\begin{array}{c}\text { Similar } \\
\text { Changes }\end{array}$ & Total \\
\hline \multirow{2}{*}{$\begin{array}{c}\text { IOL } \\
\text { placement }\end{array}$} & Bag & $\begin{array}{c}\text { Count } \\
\%\end{array}$ & $\begin{array}{c}89 \\
92.7 \%\end{array}$ & $\begin{array}{c}7 \\
7.29 \%\end{array}$ & 96 \\
\cline { 2 - 6 } & Sulcus & $\begin{array}{c}\text { Count } \\
\%\end{array}$ & $\begin{array}{c}1 \\
25 \%\end{array}$ & $\begin{array}{c}3 \\
75 \%\end{array}$ & 4 \\
\hline
\end{tabular}

Table 1. The Relationship of IOL Surface Changes and PC Changes in IOL Bag and Sulcus Insertion

IOL placed in capsular bag in 96 patients and in sulcus in 4 patients showed similar IOL surface and PC changes in 7 (7.29\%) and $3(75 \%)$ respectively which is statistically significant $\left(\chi^{2}=12.76, p=0.001\right)$. Five $(6.5 \%)$ in 77 normal patients, $2(16.8 \%)$ in 12 diabetic patients, $1(25 \%)$ in 4 hypertensive patients, $2(28.6 \%)$ in 7 patients having both hypertension and diabetes had similar IOL surface and PC changes. There is no statistical significance.

$6 \%$ of the patients had similar posterior surface of IOL changes and PC changes. $5 \%$ of the patients had similar anterior surface changes and PC changes. This is statistically insignificant.

The method of different capsulotomies (Can-opener and continuous curvilinear capsulorhexis) has been shown to have insignificant effect on IOL surface and PC changes. There was no statistical significant observation in similar changes between ECCE and SICS procedures. It has been observed that there is significant association between IOL surface changes and PC changes in IOL-sulcus insertion when compared to IOL bag insertion. Greasy deposits and crystalline changes are observed predominantly. Most of the changes were limited to zone beyond the IOL optic. The haptics and holes are free of any post-operative changes. Other capsular changes include (figure 1) - thready lines, balloon cells, fibrosis of capsule with divergent lines, wrinkles, uveal pigment deposition, polychromatic lustres were noticed on posterior capsule.

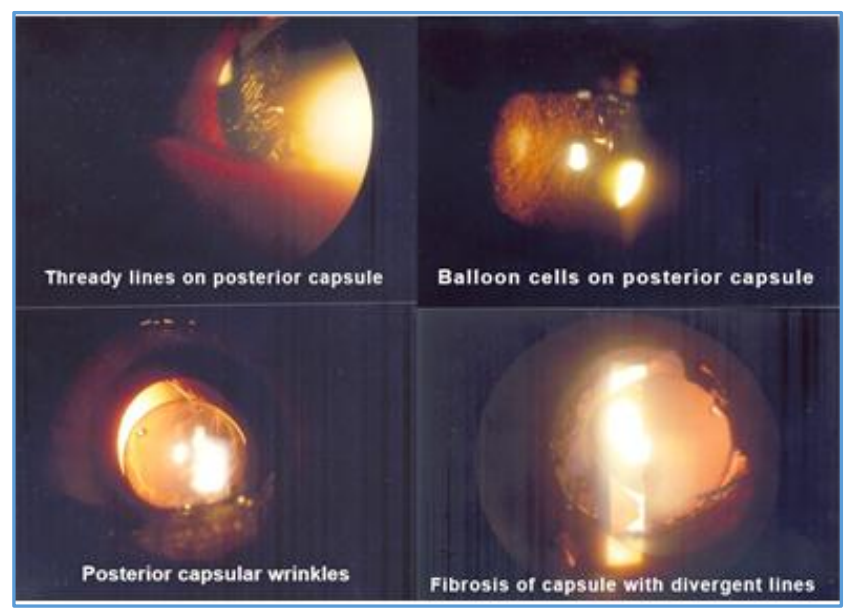

\section{DISCUSSION}

Being the most studied complication of cataract surgery, posterior capsular opacification, many researchers have reported wide range of factors influencing its development and methods to prevent this. In this study, CCC was done for 65 patients and can-opener capsulotomy for 35 patients, which showed similar IOL surface changes with PC changes in 6 and 4 patients respectively which is statistically insignificant.

The primary function of in-the-bag fixation is enhancing the IOL-optic barrier effect, which is functional and maximal when the lens optic is fully in-the-bag with direct contact with the posterior capsule. A study done by Ashworth et al showed that the patients with bag fixated IOLs had less posterior capsular opacification, fewer YAG laser capsulotomies, higher percentage of centred lenses, less inflammation, and fewer rate posterior capsular striae than those with sulcus fixated IOLs. ${ }^{4}$ In this study, there was significant association between surface changes of IOL surface and posterior capsule in the sulcus fixed IOLs than inthe-bag fixated IOLs. Out of 4 sulcus fixed IOLs, 3 showed (75\%) significant association ( $\mathrm{p}=0.001)$. This is probably due to a potential space when the LECs grow under the influence of IOL having similar changes on the surfaces of the IOL and posterior capsule.

The physical contact of a posterior chamber lens particularly with the reverse optic has been postulated to decrease the rate of capsular opacification by creating a barrier to Elschnig's pearl migration. In this study, only one type IOL is used i.e., multipiece biconvex PMMA IOL. There were 10 out of 100 patients who had similar IOL surface changes with posterior capsular changes. PMMA has been shown to have little inhibitory effect on cellular migration even when it is in direct contact with the surface on which the cells are growing. Lenses that stretch the capsule tightly against the optic i.e. posterior convex lenses or biconvex lenses especially with angled optics, will have that most inhibitory effect. The IOL material influences the PCO changes after cataract surgery and can affect the behaviour of LECs.8,14 The exact mechanism is unknown but could be explained by either mechanical or material related effects.

Nine-year Nd:YAG capsulotomy rates were $2 \%$ for square edged-PMMA IOLs versus $37 \%$ for round edged-PMMA IOLs according to Haripriya et al. ${ }^{15}$ In this study, only one type of IOL was used (PMMA IOL). Ten patients had similar IOL surface changes with posterior capsular changes.

An interesting observation was made in this study that some of the intraocular lenses had crystal in it. These lenses associated with similar changes in the posterior capsule. Although the main cause of posterior capsule opacification was found to be due to leftover lens epithelial changes, mainly the role played by the IOL itself, even after modernising them needs to be followed up as the manufacturers never disclose the full information of the content and the process as the trade secret; even polymethyl methacrylate purity varies with the manufacturers.

There are three possible explanations for higher incidence of PCO changes in diabetic patients. Firstly, cataract surgery may be more complicated. Secondly, post-operative complications (e.g.: persistent uveitis) are commoner in diabetic patients. A third possible explanation is that proliferation lens epithelial cells may be promoted by 
forward diffusion of growth factors from ischaemic retina. ${ }^{16-}$ 18

But the higher incidence of PCO and surface changes could not be explained in hypertensive patients. ${ }^{19}$

Several studies showed that IOLs have an important role in capsular opacification and capsular fibrosis, after extracapsular cataract extraction and PCIOL implantation. Anterior capsular opacification (ACO) usually occurs where capsule comes in contact with the IOL after in-the-bag implantation. Rate of ACO is relatively high with plate-haptic silicone IOLs ${ }^{20}$ and low with acrylic IOL. ${ }^{21}$ Close contact between the posterior capsule and PMMA IOL might contribute to the capsular fibrosis. ${ }^{16}$

The intraoperative procedures can prevent contraction of the capsulorhexis opening. Removing LECs during surgery helps to retain a significant larger postoperative capsular opening. ${ }^{22}$ Nishi who first described LEC removal by ultrasound, suggested that the technique prevents a postoperative fibrinous reaction. ${ }^{13}$ Snowflake or crystalline deposition in PMMA IOL biomaterial has been reported. These deposits were most commonly observed in the central and mid-peripheral portions of the IOL. ${ }^{23,24}$

\section{Limitation}

In this study, posterior capsular opacification was studied for 9 months postoperatively. As the process of posterior capsular changes takes long time and eventually happen in majority of patients, studies pursued for longer duration (2-5 years) represent the true longterm outcome. This study considers absolute error (d) of 0.05 that is relatively higher for a prevalence (p) of $6 \%$. In this write-up, prevalence of individual posterior capsular changes are not presented.

\section{CONCLUSION}

There is no significant association between intraocular lens surface changes and posterior capsular changes after extracapsular cataract extraction-posterior chamber intraocular lens implantation surgery. There is significant association between the intraocular lens surface changes and posterior capsular changes in "IOL-sulcus insertion" when compared to "IOL-bag insertion". Other factors like type of surgery, type of capsulotomy (can-opener and capsulorhexis), systemic diseases have no significant effect on similar intraocular lens surface changes and posterior capsular changes.

\section{REFERENCES}

[1] Maedel S, Buehl W, Findl O. Intraocular lens optic edge design for the prevention of posterior capsule opacification after cataract surgery. In: Cochrane database of systematic reviews. John Wiley \& Sons, Ltd.,

2017.

http://onlinelibrary.wiley.com/doi/10.1002/146518 58.CD012516/abstract

[2] Awasthi N, Guo S, Wagner BJ. Posterior capsular opacification: a problem reduced but not yet eradicated. Arch Ophthalmol 2009;127(4): 555-62.

[3] Spalton DJ, Russell SL, Evans-Gowing R, et al. Effect of total lens epithelial cell destruction on intraocular lens fixation in the human capsular bag. J Cataract Refract Surg 2014;40(2):306-12.
[4] Ashworth JL, Lloyd IC. Intraocular lens implantation in the capsular bag and posterior capsulotomy techniques. In: Lloyd IC, Lambert SR. eds. Congenital cataract. Switzerland: Springer International Publishing 2017:101-9. http://link.springer.com/chapter/10.1007/978-3319-27848-3_9.

[5] Pandey SK, Apple DJ, Werner L, et al. Posterior capsule opacification: a review of the aetiopathogenesis, experimental and clinical studies and factors for prevention. Indian J Ophthalmol 2004;52(2):99-112.

[6] Nibourg LM, Gelens E, Kuijer R, et al. Prevention of posterior capsular opacification. Exp Eye Res 2015;136:100-15.

[7] Kahraman G, Schrittwieser H, Walch M, et al. Anterior and posterior capsular opacification with the Tecnis ZCB00 and AcrySof SA60AT IOLs: a randomised intraindividual comparison. $\mathrm{Br} \mathrm{J}$ Ophthalmol 2014;98(7):905-9.

[8] Kahraman G, Amon M, Ferdinaro C, et al Intraindividual comparative analysis of capsule opacification after implantation of 2 single-piece hydrophobic acrylic intraocular lenses models. Threeyear follow-up. J Cataract Refract Surg 2015;41(5): 990-6.

[9] Sachsenweger R. Illustrated handbook of ophthalmology. Butterworth-Heinemann 2014:165.

[10] Yamada K, Nagamoto T, Yozawa H, et al. Effect of intraocular lens design on posterior capsule opacification after continuous curvilinear capsulorhexis. J Cataract Refract Surg 1995;21(6):697-700.

[11] Trinavarat A, Atchaneeyasakul L, Udompunturak S. Neodymium: YAG laser damage threshold of foldable intraocular lenses. J Cataract Refract Surg 2001;27 (5):775-80.

[12] Sinha R, Shekhar H, Sharma N, et al. Posterior capsular opacification: a review. Indian J Ophthalmol 2013;61(7):371-6.

[13] Nishi O, Nishi K, Hikida M. Removal of lens epithelial cells by dispersion with enzymatic treatment followed by aspiration. Ophthalmic Surg Lasers Imaging Retina 1991;22(8):444-50.

[14] Wang GQ, Dang YL, Huang Q, et al. In vitro evaluation of the effects of intraocular lens material on lens epithelial cell proliferation, migration and transformation. Curr Eye Res 2017;42(1):72-8.

[15] Haripriya A, Chang DF, Vijayakumar B, et al. Longterm posterior capsule opacification reduction with square-edge polymethylmethacrylate intraocular lens. Ophthalmology 2017;124(3):295-302.

[16] Schaumberg DA, Dana MR, Christen WG, et al. A systematic overview of the incidence of posterior capsule opacification. Ophthalmology 1998;105(7): 1213-21.

[17] Tetz MR, Nimsgern C. Posterior capsule opacification: Part 2: clinical findings. J Cataract Refract Surg 1999;25(12):1662-74.

[18] Hayashi K, Hayashi H, Nakao F, et al. Posterior capsule opacification after cataract surgery in patients with diabetes mellitus. Am J Ophthalmol 2002;134(1):10-6. 
[19] Ebihara Y, Kato S, Oshika T, et al. Posterior capsule opacification after cataract surgery in patients with diabetes mellitus. J Cataract Refract Surg 2006;32(7):1184-7.

[20] Werner L, Pandey SK, Escobar-Gomez M, et al. Anterior capsule opacification: a histopathological study comparing different IOL styles. Ophthalmology 2000;107(3):463-71.

[21] Park TK, Chung SK, Baek NH. Changes in the area of the anterior capsule opening after intraocular lens implantation. J Cataract Refract Surg 2002;28(9):1613-7.

[22] Joo CK, Shin JA, Kim JH. Capsular opening contraction after continuous curvilinear capsulorhexis and intraocular lens implantation. J Cataract Refract Surg 1996;22(5):585-90.
[23] Apple DJ, Peng Q, Arthur SN, et al. Snowflake degeneration of polymethyl methacrylate posterior chamber intraocular lens optic material: A newly described clinical condition caused by unexpected late opacification of polymethylmethacrylate. The authors have no proprietary interest in any of the techniques, materials, devices, or equipment used in this study. Ophthalmology 2002;109(9):1666-75.

[24] Peng Q, Apple DJ, Arthur SN, et al. Snowflake opacification of poly (methyl methacrylate) intraocular lens optic biomaterial: a newly described syndrome. Int Ophthalmol Clin 2001;41(3):91-107. 